\title{
Article \\ Proliferation to Apoptosis Tumor Cell Ratio as a Biomarker to Improve Clinical Management of Pre-Malignant and Symptomatic Plasma Cell Neoplasms
}

\author{
María A. Vasco-Mogorrón ${ }^{1}$, José A. Campillo ${ }^{1}$, Adela Periago ${ }^{2}$, Valentin Cabañas ${ }^{3}$, Mercedes Berenguer ${ }^{4}$, \\ María C. García-Garay ${ }^{3}$, Lourdes Gimeno ${ }^{1,5}$, María F. Soto-Ramírez ${ }^{1}$, María D. Martínez-Hernández ${ }^{1}$, \\ Manuel Muro ${ }^{1}$ (D) and Alfredo Minguela ${ }^{1, *(D)}$
}

check for updates

Citation: Vasco-Mogorrón, M.A.; Campillo, J.A.; Periago, A.; Cabañas, V.; Berenguer, M.; García-Garay, M.C.; Gimeno, L.; Soto-Ramírez, M.F.; Martínez-Hernández, M.D.; Muro, M.; et al. Proliferation to Apoptosis Tumor Cell Ratio as a Biomarker to Improve Clinical Management of Pre-Malignant and Symptomatic Plasma Cell Neoplasms. Int. J. Mol. Sci. 2021, 22, 3895. https://doi.org/ $10.3390 /$ ijms22083895

Academic Editor: Albrecht Reichle

Received: 15 March 2021

Accepted: 6 April 2021

Published: 9 April 2021

Publisher's Note: MDPI stays neutral with regard to jurisdictional claims in published maps and institutional affiliations.

Copyright: (C) 2021 by the authors Licensee MDPI, Basel, Switzerland. This article is an open access article distributed under the terms and conditions of the Creative Commons Attribution (CC BY) license (https:/ / creativecommons.org/licenses/by/ $4.0 /)$.
1 Immunology Service, Clinic University Hospital Virgen de la Arrrixaca (HCUVA), Biomedical Research Institute of Murcia (IMIB), 30120 Murcia, Spain; atlantisady@gmail.com (M.A.V.-M.); josea.campillo@carm.es (J.A.C.); lourdes.gimeno@carm.es (L.G.); mariaf.soto@carm.es (M.F.S.-R.); lola.mtz.hdz@gmail.com (M.D.M.-H.); manuel.muro@carm.es (M.M.)

2 Hematology Service, General University Hospital Rafael Méndez, Biomedical Research Institute of Murcia (IMIB), 30813 Murcia, Spain; adelam.periago@carm.es

3 Hematology Service, Clinic University Hospital Virgen de la Arrrixaca (HCUVA), Biomedical Research Institute of Murcia (IMIB), 30120 Murcia, Spain; valentin.cabanas@carm.es (V.C.); mcarmen.garcia35@carm.es (M.C.G.-G.)

4 Hematology Service, General University Hospital Santa Lucía, Biomedical Research Institute of Murcia (IMIB), 30202 Murcia, Spain; mercedes.berenguer@carm.es

5 Human Anatomy Department, Medicine Faculty, Biomedical Research Institute of Murcia (IMIB), Murcia University, 30120 Murcia, Spain

* Correspondence: alfredo.minguela@carm.es

Abstract: Proliferation and apoptosis of neoplastic cells are prognostic biomarkers in plasma cell neoplasms (PCNs). The prognostic capacity of proliferation to apoptosis ratio (Ratio-PA) in the era of immunomodulatory treatments is re-evaluated in 316 gammopathy of undetermined significance (MGUS), 57 smoldering multiple myeloma (SMM), and 266 multiple myeloma (MM) patients. RatioPA of $0.77 \pm 0.12,1.94 \pm 0.52$, and $11.2 \pm 0.7(p<0.0001)$ were observed in MGUS, SMM, and MM patients. Ten-year overall survival (10y-OS) rates for patients with low $/$ high Ratio-PA were $93.5 \% / 77.3 \%$ $p<0.0001)$ for MGUS, $82.5 \% / 64.7 \%(p<0.05)$ for SMM, and 62.3\%/47.0\% $(p<0.05)$ for MM. For patients with low, intermediate, and high risk, 10y-OS for low /high Ratio-PA were 95.5\%/72.9\% $(p<0.0001), 74.2 \% / 50.4 \%(p<0.0001)$, and 35.3\%/20.0\% $(p=0.836)$, respectively. Ratio-PA was an independent prognostic factor for OS $(\mathrm{HR}=2.119, p<0.0001$, Harrell-C-statistic $=0.7440 \pm 0.0194)$ when co-analyzed with sex, age, and standard risk. In patients with Ratio-PA ${ }^{\text {high }}$, only first-line therapy with VRd/VTd, but not PAD/VCD, coupled with ASCT was associated with high 10y-OS $(82.7 \%)$. Tumor cell Ratio-PA estimated at diagnosis offers a prognostic biomarker that complements standard risk stratification and helps to guide the clinical management of pre-malignant and symptomatic PCNs. Every effort should be made to provide first-line therapies including VTd or VRd associated with ASCT to patients with Ratio-PA ${ }^{\text {high }}$ at higher risk of progression and death.

Keywords: plasma cell neoplasm; MGUS; SMM; MM; treatment; proliferation; apoptosis

\section{Introduction}

Multiple myeloma (MM) is a plasma cell neoplasm (PCN) with a relapsing clinical course requiring several lines of therapy in most patients. Nonetheless, novel standard first-line treatments combining immunomodulatory drugs (lenalidomide, thalidomide, or pomalidomide, -IMiDs-), proteasome inhibitors (bortezomib, Carfilzomib, or Ixazomib, -PIs-), and monoclonal antibody as daratumumab and tandem autologous stem cell transplantation (ASCT) have increased the rate of complete response (CR) and prolonged 
treatment-free and survival periods [1]. Unfortunately, not all patients are eligible for ASCT, so they have to receive treatments that, although improved in recent years, are not as effective as those associated with ASCT. Nonetheless, regardless of the type of treatment, the disease displays substantial clinical heterogeneity in presentation and course, thus underlining the need for biomarkers that allow us to adapt the therapy not only to the patient's biological and clinical conditions, but also to the real risk of the disease. Currently, there are several risk stratification systems depending on the type of $\mathrm{PCN}$, from premalignant monoclonal gammopathy of undetermined significance (MGUS) [2-4] and smoldering MM (SMM) [2,3,5-7] to the symptomatic MM [8]. MGUS is the most common PCN, with a prevalence of $3.2 \%$ in the general population older than 50 , and increasing with age [9-11]. Although the progression rates to MM in asymptomatic MGUS and SMM are about $1 \%$ and $10 \%$ per year, respectively $[11,12]$, prognostic biomarkers are also needed in MGUS and SMM for counseling, clinical care, and follow-up, and for the design of clinical studies in patients at high risk [9].

In MM, biochemical and genetic prognostic factors such as albumin, beta-2 microglobulin (b2m), lactate dehydrogenase (LDH), and the high-risk cytogenetic abnormalities $\operatorname{del}(17 p)$ and $t(4 ; 14)$ detected by fluorescent in situ hybridization (FISH) have been incorporated in the Revised International Staging System (RISS), to provide a powerful prognostic tool to risk-stratify patients at diagnosis [8]. However, the presence of high-risk cytogenetics and the concurrence of elevated levels of $\mathrm{LDH}$ and $\mathrm{b} 2 \mathrm{~m}$ are rarely observed at the onset of the disease; therefore, RISS generally underestimates high-risk and overestimates intermediate-risk patients and, as a consequence, patients at intermediate risk show notable clinical variability, indicating that some of these patients could have benefited from more effective first-line treatments [13].

The myelomatous plasma cell (PC) proliferation index provides insight into the biology of the neoplastic cell, and it is a strong prognostic marker in active MM [14-16] and SMM [17,18] and even in MGUS [19]. However, the expansion of myeloma neoplastic clone is determined by a balance between proliferation on the one hand, and induction or blockade of apoptosis on the other hand. In fact, myeloma is characterized by very slow proliferation of malignant $\mathrm{PC}$, suggesting that pathogenesis and resistance to treatment of these cells within the bone marrow (BM) may be related to resistance to apoptosis [20]. Imbalances in the expression of the Bcl-2 family members (higher expression of the antiapoptotic Bcl-2 and Mcl-1, and lower of the proapoptotic Bax [21]) result in defects in programmed cell death, which are associated with malignancy, aggressiveness, and chemoresistance of tumors [20]. Various therapeutic modalities that are effective in MM modulate levels of the $\mathrm{Bcl}-2$ family members, the expression of which is primarily regulated by p53, nuclear factor $\mathrm{\kappa B}$, and STAT factors [20]. Both IMiDs and PIs inhibit the NF- $\mathrm{kB}$ cell survival pathway and stimulate apoptosis of malignant PCs [22,23]. Besides, PIs stimulate the expression of the proapoptotic Fas ligand/receptor members [23].

In contrast with solid tumors, where higher proliferation rates are associated with increased apoptosis of neoplastic cells, [24] in PCNs, an inverse relationship between PC proliferation and apoptosis rates has been well-established [25]. Nonetheless, an elevated proliferation to apoptosis ratio (Ratio-PA) of BM-PC was an independent prognostic factor associated with shorter patient's overall survival (OS) both in solid tumors (cervical adenocarcinoma [26] and glioblastoma multiforme [27]) and in MM [14-16]. In MGUS and SMM, high Ratio-PA of BM-PC has been associated with active disease and progression, [28,29] but its prognostic value in patient's OS has been poorly investigated.

This study shows how the combined analysis of BM-PC proliferation and apoptosis rates, easily estimated by flow cytometry, complements standard risk stratification and increases their prognostic capacity to identify high-risk MGUS patients, most of whom will progress or die in the first few years after diagnosis. Besides, it also contributes to identification of SMM and risk-I/-II MM patients who, due to their higher risk of progression and death, could benefit from the most effective therapies reserved for MM patients with high-risk cytogenetics. The prognostic capacity remained valid even in MM 
patients who relapsed after stringent $\mathrm{CR}(\mathrm{sCR})$ with negative minimal residual disease (MRD), and therefore, it would be equally useful for the most effective drugs used in current clinical practice.

\section{Results}

\subsection{Patient Characteristics}

Table 1 presents biological, clinical, and therapeutic characteristics of patients. Ten-year progression-free survival (10y-PFS) and OS (10y-OS) rates were $86.4 \%$ and $90.8 \%$ for MGUS, $50.0 \%$ and $75.0 \%$ for SMM, and $40.6 \%$ and $54.5 \%$ for MM. According to the standard risk stratification (risk-I, -II, and -III), MGUS showed 10y-PFS of $93.8 \%, 78.4 \%$, and $50.0 \%$ $(p<0.0001)$ and $10 \mathrm{y}-\mathrm{OS}$ of $95.3 \%, 85.6 \%$, and $62.5 \%(p<0.0001)$; SMM showed 10y-PFS of $58.3 \%, 44.4 \%$, and $20.0 \%(p<0.05)$ and $10 \mathrm{y}-\mathrm{OS}$ of $87.5 \%, 70.4 \%$, and $20.0 \%(p<0.01)$; and MM showed 10y-PFS of $44.4 \%, 36.1 \%$, and $13.3 \%(p<0.0001)$ and $10 \mathrm{y}-\mathrm{OS}$ of $79.6 \%, 47.4 \%$, and $16.7 \%(p<0.0001)$. According to the type of treatment, 10y-PFS and 10y-OS rates were $26.8 \%$ and $40.2 \%$ for No-ASCT ( $p<0.05$ ), 35.5\% and $66.1 \%$ for ASCT with PAD or VCD, and $60.7 \%$ and $85.5 \%$ for ASCT with VTd or VRd (Figure 1).

Table 1. Baseline characteristics of patients at the time of diagnosis.

\begin{tabular}{|c|c|c|c|}
\hline & $\begin{array}{l}\text { MGUS } \\
(n=316)\end{array}$ & $\begin{array}{c}\text { SMM } \\
(n=57)\end{array}$ & $\begin{array}{c}\text { MM } \\
(n=266)\end{array}$ \\
\hline \multicolumn{4}{|c|}{ Demographic, Biochemical and Immunological Characteristics } \\
\hline Age, years, Mean \pm SEM & $67.4 \pm 0.7$ & $67.5 \pm 1.6$ & $67.6 \pm 0.7$ \\
\hline Female, $n(\%)$ & $143(45.3 \%)$ & $34(59.6 \%)$ & $130(48.9 \%)$ \\
\hline Hemoglobin, g/dL, Mean \pm SEM & $14.3 \pm 5.7$ & $12.9 \pm 2.51$ & $10.8 \pm 1.7^{* * *}$ \\
\hline Serum calcium, $\mathrm{g} / \mathrm{dL}$, Mean $\pm \mathrm{S}$ EM & $9.45 \pm 0.04$ & $9.46 \pm 0.11$ & $9.70 \pm 0.09 * *$ \\
\hline Serum creatinine, $\mathrm{mg} / \mathrm{dL}$, Mean $\pm \mathrm{SEM}$ & $1.20 \pm 0.07$ & $1.04 \pm 0.07$ & $1.73 \pm 0.13 *$ \\
\hline Serum albumin $<3.5 \mathrm{~g} / \mathrm{dL}, n(\%)$ & $29(9.2 \%)$ & $6(10.5 \%)$ & $91(34.2 \%)^{* * *}$ \\
\hline Serum 2-microglobulin $\geq 3.5 \mathrm{mg} / \mathrm{dL}, n(\%)$ & $93(29.4 \%)$ & $18(31.5 \%)$ & $159(59.8 \%)^{* * *}$ \\
\hline $\mathrm{LDH} \geq$ upper limit of normal, $n(\%)$ & $52(16.4 \%)$ & $9(15.7 \%)$ & $59(22.2 \%)$ \\
\hline Serum M-protein, $\mathrm{g} / \mathrm{dL}$, Mean \pm SEM & $1.04 \pm 0.08$ & $1.68 \pm 0.13 *$ & $2.81 \pm 0.20^{* * *}$ \\
\hline Bence Jones protein, $n(\%)$ & $106(33.5 \%)$ & $30(52.6 \%) *$ & $186(69.9 \%)^{* * *}$ \\
\hline Free light chain ratio $>20, n(\%)$ & $109(34.5 \%)$ & $32(56.1 \%)^{* *}$ & $195(73.3 \%)^{* * *}$ \\
\hline IgG gammopathy, $n(\%)$ & $227(71.8 \%)$ & $33(57.9 \%) *$ & $143(53.7 \%)^{* * *}$ \\
\hline Immunoparesis, $n(\%)$ & $111(35.1 \%)$ & $35(61.4 \%)^{* * *}$ & $242(90.9 \%) * * *$ \\
\hline \multicolumn{4}{|c|}{ Bone Marrow Plasma Cells (BM-PC) Counts } \\
\hline Total BM-PC histology, \% (Mean \pm SEM) & $4.71 \pm 0.16$ & $16.85 \pm 1.5^{* * *}$ & $33.52 \pm 1.6^{* * *}$ \\
\hline Total BM-PC flow cytometry, \% (Mean \pm SEM) & $1.08 \pm 0.09$ & $3.54 \pm 0.54$ & $13.01 \pm 1.5^{* * *}$ \\
\hline \multicolumn{4}{|c|}{ Fluorescent In Situ Hybridization (FISH) on Purified BM-PCs } \\
\hline $\operatorname{del}(17 \mathrm{p}), n(\%)$ & $3(0.9 \%)$ & $2(3.5 \%)$ & $23(8.6 \%) * * *$ \\
\hline $\mathrm{t}(4 ; 14)$ or $\mathrm{t}(14 ; 16), n(\%)$ & $2(0.7 \%)$ & $2(3.5 \%)$ & $14(5.2 \%) * *$ \\
\hline Gain of 1q21 & $35(11.0 \%)$ & $17(30.0 \%)^{* *}$ & $115(43.2 \%) * * *$ \\
\hline Other alterations, $n(\%)^{1}$ & $32(10.1 \%)$ & $7(12.3 \%)$ & $51(20.3 \%) * *$ \\
\hline No abnormalities, $n(\%)$ & $253(80.1 \%)$ & $30(52.6 \%) * *$ & $77(28.9 \%)^{* * *}$ \\
\hline Not available, $n(\%)$ & $55(17.4 \%)$ & $1(1.75 \%) *$ & $35(13.15 \%)$ \\
\hline \multicolumn{4}{|c|}{ Clinical Characteristics } \\
\hline Osteolytic lesions, $n(\%)$ & $8(2.5 \%)$ & $4(7.0 \%)$ & $147(55.3 \%)^{* * *}$ \\
\hline Renal insufficiency, $n(\%)$ & $85(26.9 \%)$ & $14(24.50 \%)$ & $97(36.4 \%) *$ \\
\hline Additional cardio-respiratory diseases, $n(\%)$ & $81(25.6 \%)$ & $15(26.3 \%)$ & $80(30.1 \%)$ \\
\hline Additional endocrine diseases, $n(\%)$ & $72(22.8 \%)$ & $16(28.1 \%)$ & $63(23.7 \%)$ \\
\hline Additional rheumatologic diseases, $n(\%)$ & $34(10.7 \%)$ & $4(7.01 \%)$ & $12(4.5 \%)$ \\
\hline Additional oncological malignances, $n(\%)$ & $23(7.2 \%)$ & $7(12.3 \%)$ & $25(10.1 \%)$ \\
\hline Additional hematological diseases, $n(\%)$ & $14(5.1 \%)$ & $5(8.9 \%)$ & $27(10.3 \%)$ \\
\hline Risk stratification Low/Intermediate/High, $n^{2}$ & $152 / 142 / 11$ & $26 / 28 / 6$ & $65 / 165 / 32$ \\
\hline
\end{tabular}


Table 1. Cont.

\begin{tabular}{|c|c|c|c|}
\hline & $\begin{array}{l}\text { MGUS } \\
(n=316)\end{array}$ & $\begin{array}{c}\text { SMM } \\
(n=57)\end{array}$ & $\begin{array}{c}\text { MM } \\
(n=266)\end{array}$ \\
\hline \multicolumn{4}{|c|}{ Treatments ${ }^{3}$} \\
\hline No ASCT with VMP, Vd or Rd, $n(\%)$ & $17(5.3 \%)^{4}$ & $10(17.5 \%)^{4}$ & $149(56.1 \%)$ \\
\hline ASCT with PAD or VCD, $n(\%)$ & $0(0.0 \%)$ & $3(5.3 \%)^{4}$ & $57(21.4 \%)$ \\
\hline ASCT with VTd or VRd, $n(\%)$ & $2(0.6 \%)^{4}$ & $11(19.3 \%)^{4}$ & $48(18.0 \%)$ \\
\hline Palliative & - & - & $12(4.5 \%)$ \\
\hline
\end{tabular}

${ }^{1} \operatorname{del}(13 q)$, other IGH translocations, hyper- or hypo-diploidy on Chromosome 5, 9, 13, 14, 15 or 17. ${ }^{2}$ Risk stratification following standardized criteria for MGUS and SMM (score $-0=$ low, $1=$ intermediate, and $2=$ high) $[7,30]$ and MM (RISS $-\mathrm{I}=$ low, II $=$ intermediate and III = high) [8]. ${ }^{3}$ ASCT: autologous stem cell transplantation; A: doxorubicin; C: cyclophosphamide; d: low-dose dexamethasone; M: melphalan, P: prednisone; V: bortezomib; R: lenalidomide; T: thalidomide. ${ }^{4}$ MGUS and SMM patients who progressed to symptomatic PCNs and required treatment during the follow-up. ${ }^{*} p<0.05 ;{ }^{* *} p<0.01$ and ${ }^{* * *} p<0.001$ MGUS vs. SMM or MGUS vs. MM (ANOVA and LSD tests or Chi square test).
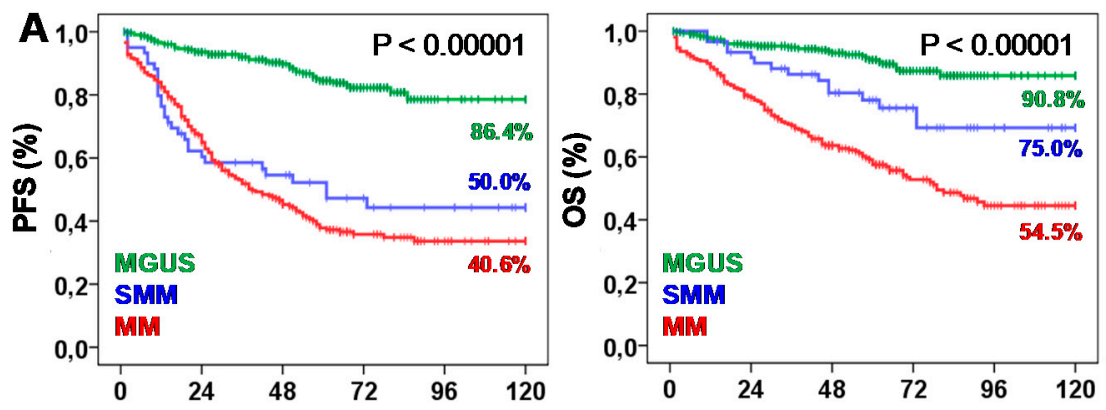

B

Standard risk stratification (sRisk)

\begin{tabular}{lccc}
\multicolumn{4}{c}{ 10-year PFS (\%) } \\
\hline \multirow{3}{*}{ sRisk-I } & 94.4 & 58.3 & 55.9 \\
sRUS & SMM & MM \\
sRisk-II & 77.9 & 50.0 & 39.0 \\
sRisk-III & 63.6 & 20.0 & 15.6 \\
P $<$ & 0.0001 & 0.05 & 0.0001 \\
\hline
\end{tabular}
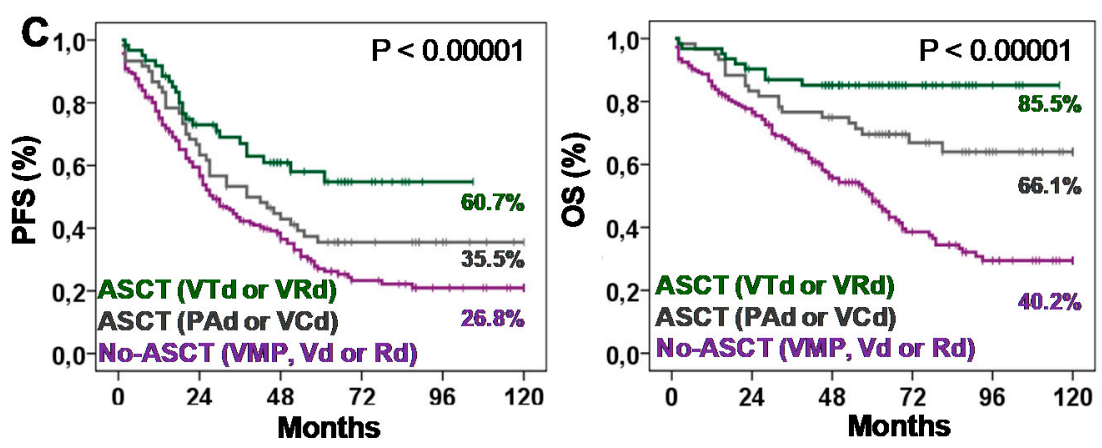

\begin{tabular}{lccc}
\multicolumn{4}{c}{ 10-year OS (\%) } \\
\hline \multirow{3}{*}{ sRisk-I } & MGUS & SMM & MM \\
\cline { 2 - 4 } sRisk-II & 85.5 & 87.5 & 83.8 \\
sRisk-III & 72.7 & 75.0 & 50.0 \\
P $<$ & 0.0001 & 0.01 & 0.0001 \\
\hline
\end{tabular}

Figure 1. Survival of patients according to the type of plasma cell neoplasm (PCN), their standard risk or the type of first-line treatment. (A) Kaplan-Meier and Log-rank tests for Progression-Free (PFS) and Overall Survival (OS) according to the type of PCN: monoclonal gammopathy of undetermined significance (MGUS), smoldering multiple myeloma (SMM), or multiple myeloma (MM). Ten-year survivals are shown for each PCN type. (B) Ten-year PFS and OS rates (estimated with Kaplan-Meier and Log-rank tests) according to the standard risk (sRisk) for MGUS [30], SMM [7], and MM [8] patients: low (sRisk-I), intermediate (sRisk-II), and high (sRisk-III). (C) Kaplan-Meier and Log-rank tests for PFS and OS according to the type of first-line treatment: No-autologous stem cell transplantation (ASCT) with VMP, Vd or Rd; ASCT with PAD or VCD; or ASCT with VTd or VRd. Ten-year survivals are shown for each treatment.

\subsection{Prognostic Value of BM-PC Proliferation to Apoptosis Ratio (Ratio-PA)}

First we analyzed the biological characteristics of PCs infiltrating the BM in MGUS, SMM, and MM. Increasing total BM-PCs in the histology analysis $(4.72 \pm 0.16 \%, 15.9 \pm 1.5 \%$ and $3.5 \pm 1.6 \%, p<0.0001)$ and BM-PC proliferation rates $(1.86 \pm 0.1 \%, 2.17 \pm 0.23 \%$ and $3.26 \pm 0.19 \%, p<0.0001)$, but decreasing apoptotic rates $(9.53 \pm 0.5 \%, 6.41 \pm 1.1$, and $4.34 \pm 0.39, p<0.0001$ ) were observed for MGUS, SMM, and MM patients (Figure 2A). A proliferation-to-apoptosis ratio (Ratio-PA) of BM-PC was calculated for each patient and analyzed in MGUS, SMM, and MM stages $(0.77 \pm 0.12,1.94 \pm 0.52$, and $11.2 \pm 0.7$, $p<0.0001$; Figure 2B). 
A

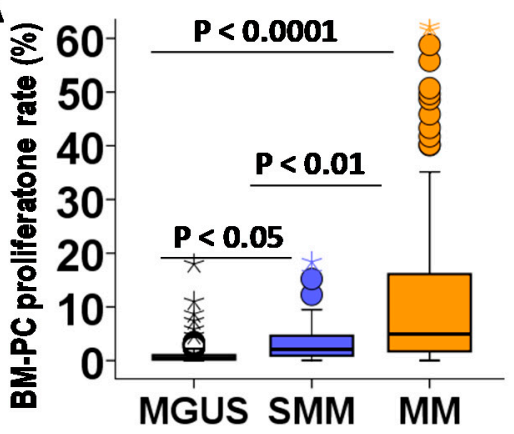

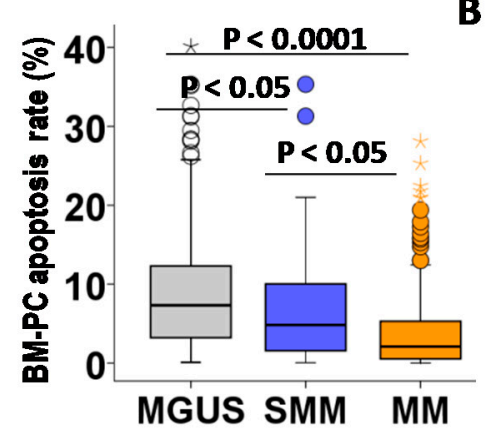

B

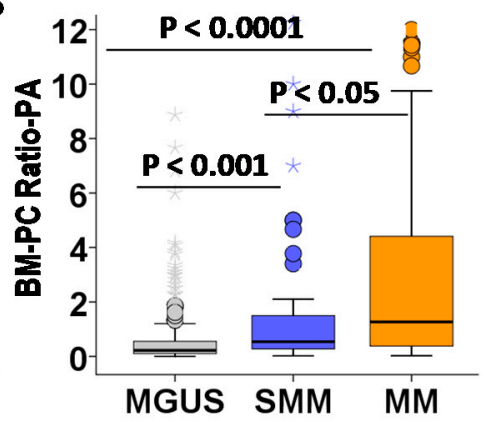

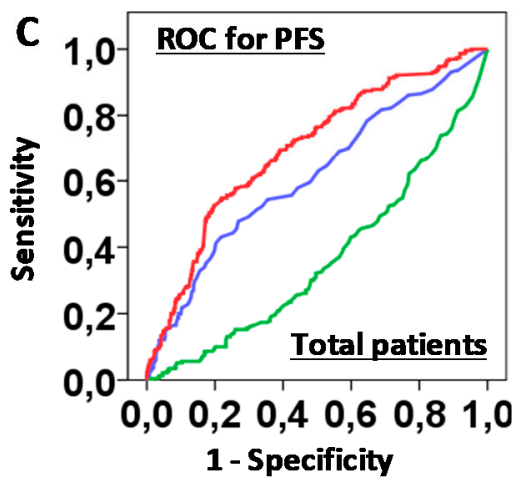

Proliferation rate (AUC=0.61)

Apoptosis rate (AUC $=0.64$ )

Ratio-PA (AUC=0.72)

\begin{tabular}{lccc} 
Ratio-PA & MGUS & SMM & MM \\
\hline Cutoff & 0.91 & 1.27 & 1.15
\end{tabular}

$\begin{array}{llll}\text { AUC } & 0.64 & 0.63 & 0.65\end{array}$

Sensitivity (\%) $\quad 55.5 \quad 54.1 \quad 62.1$

$\begin{array}{llll}\text { Specificity (\%) } & 82.1 & 87.1 & 65.2\end{array}$

Figure 2. Biological characteristic of bone marrow plasma cells (BM-PCs) in patients with monoclonal gammopathy of undetermined significance (MGUS), smoldering multiple myeloma (SMM), or multiple myeloma (MM) and their prognostic capacity for progression-free survival (PFS). (A) Quantification of BM-PCs proliferation and apoptosis rates in MGUS, SMM, and MM patients. (B) Proliferation-to-apoptosis ratio (Ratio-PA) of BM-PC in MGUS, SMM, and MM. (C) Receiver-operating characteristic (ROC) analysis of proliferation and apoptosis rates and Ratio-PA for PFS in total patients. Table shows cutoff values with maximum prognostic capacity for PFS, area under the curve (AUC), sensibility, and specificity of Ratio-PA in MGUS, SMM, and MM patients.

The prognostic capacity for PFS of BM-PC proliferation and apoptosis rates and RatioPA were evaluated by ROC analysis in total PCN patients (Figure 2C). Since Ratio-PA showed higher area under the curve $(\mathrm{AUC}=0.72)$ than proliferation $(\mathrm{AUC}=0.61)$ and apoptosis (AUC $=0.64$ ) rates, cutoffs for Ratio-PA with the highest prognostic capacity for PFS were estimated for MGUS (cutoff $=0.91$, sensitivity $=55.5 \%$ and specificity $=82.1 \%$ ), SMM (cutoff $=1.27$, sensitivity $=51.1 \%$ and specificity $=87.1 \%$ ), and MM (cutoff $=1.15$, sensitivity $=62.5 \%$ and specificity $=65.2 \%$ ). Finally, the proportion of patients over their correspondent cutoffs (Ratio-PA ${ }^{\text {high }}$ ) were estimated for MGUS, SMM, and MM (16.8\%, $29.8 \%$ and $50.8 \%, p<0.0001$ ).

Next, we explored the prognostic capacity of the Ratio-PA for PFS and OS of MGUS, SMM, and MM patients by Kaplan-Meier analysis (Figure 3A). The 10y-PFS and 10y-OS rates for patients with Ratio-PA ${ }^{\text {high }}$ vs. Ratio-PA ${ }^{\text {low }}$ were $90.1 \%$ vs. $67.9 \% \%(p<0.0001)$ and $93.5 \%$ vs. $77.3 \%$ ( $p<0.0001)$ for MGUS, $57.5 \%$ vs. $35.3 \%(p=0.078)$ and $82.5 \%$ vs. $64.7 \%(p<0.05)$ for SMM, and $49.2 \%$ vs. $32.1 \%(p<0.05)$ and $62.3 \%$ vs. $47.0 \%(p<0.05)$ for $\mathrm{MM}$, respectively.

Cox regression analysis of total PCN showed that Ratio-PA was an independent prognostic factor for PFS $(\mathrm{HR}=2.289, p<0.0001$, Harrell C-statistic $=0.7104 \pm 0.0193)$ and OS (HR $=2.119, p<0.0001$, Harrell C-statistic $=0.7440 \pm 0.0194)$ when analyzed together with sex (shorter PFS and OS for men than women), age (shorter PFS and OS for elders), and standard risk stratification $(\mathrm{HR}=2.247, p<0.0001$ for PFS and HR $=3.280, p<0.0001$ for OS; Figure 3B). Comparable HR results were observed when MGUS, SMM, and MM stages were analyzed separately (see Figure $3 \mathrm{C}$ for details). 

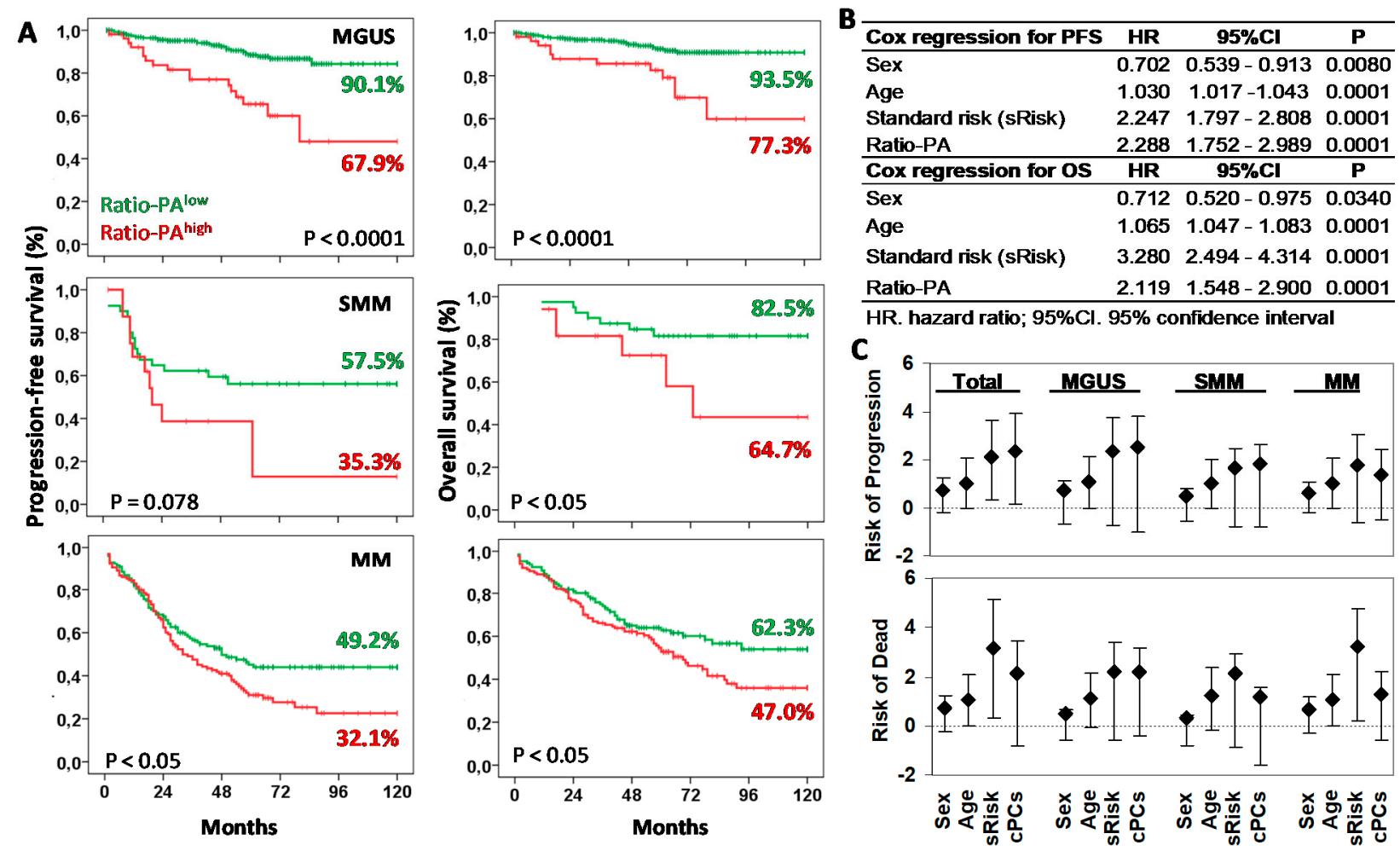

Figure 3. Prognostic capacity of Ratio-PA ${ }^{\text {high }}$ for progression-free survival (PFS) and overall survival (OS) of plasma cell neoplasm (PCN) stages. (A) Kaplan-Meier and Log-rank tests for PFS and OS according to the high or low Ratio-PA in patients with monoclonal gammopathy of undetermined significance (MGUS), smoldering multiple myeloma (SMM), or multiple myeloma (MM). Ten-year PFS and OS are indicated in the plots. (B) Cox regression analysis for PFS and OS for sex, age, standard risk stratification (sRisk), and Ratio-PA of bone marrow plasma cells in total patients. (C) Hazard ratio (HR) and 95\% confidence interval for progression or death in total, MGUS, SMM, and MM patients observed in the Cox regression analysis.

\subsection{Ratio-PA Complements the Prognostic Capacity of Standard Risk Stratification in PCNs}

The Ratio-PA showed prognostic capacity in pre-malignant and symptomatic PCNs not only by itself, but also complementing the standard risk stratification estimated in each type of PCN following current standard criteria, especially for low- (Risk-I) or intermediate(Risk-II) risk patients. According to the low/high Ratio-PA, we observed 10y-PFS and 10y-OS rates of $85.4 \% / 47.9 \%(p<0.0001)$ and $95.5 \% / 72.9 \%(p<0.0001)$ for low-risk patients; $65.7 \% / 35.4 \%(p<0.0001)$ and $74.2 \% / 50.4 \%(p<0.0001)$ for intermediate-risk patients; and $23.5 \% / 16.0 \%(p=0.703)$ and $35.3 \% / 20.0 \%(p=0.836)$ for high-risk patients (Figure 4 , left plots). It is noteworthy that $24.0 \%$ of standard low-risk patients who had Ratio-PA ${ }^{\text {high }}$ showed PFS and OS curves close to those seen in intermediate-risk patients; and in the same way, $35.2 \%$ of intermediate-risk patients who had Ratio-PA ${ }^{\text {high }}$ showed PFS and OS curves that were closed to those seen in high-risk patients.

Similar results were observed for each type of PCN. According to the low $/$ high Ratio-PA, MGUS, SMM, and MM patients showed 10y-PFS rates of $95.7 \% / 83.3 \%(p<0.05)$, $68.4 \% / 33.3 \%$ and $58.6 \% / 48.6 \%$ for sRisk-I; $84.2 \% / 60.0 \%(p<0.01), 50.0 \% / 44.4 \%$ and $47.1 \% / 29.1 \%(p<0.05)$ for sRisk-II, and $60.0 \% / 45.0 \%, 33.3 \% / 10.0 \%$ and $25.0 \% / 10.5 \%$ for sRisk-III, respectively; and 10y-OS rates were $97.1 \% / 88.8 \%, 94.7 \% / 66.6 \%(p<0.01)$ and 93.1\%/74.2\% $(p<0.05)$ for sRisk-I, 89.5\%/73.3\% $(p<0.05), 77.8 \% / 66.7 \%$ and $55.2 \% / 43.0 \%$ for sRisk-II, and $80.3 \% / 60.1 \%, 33.3 \% / 20.0 \%$ and $25.0 \% / 10.5 \%$ for sRisk-III, respectively (Figure 4, right plots). 


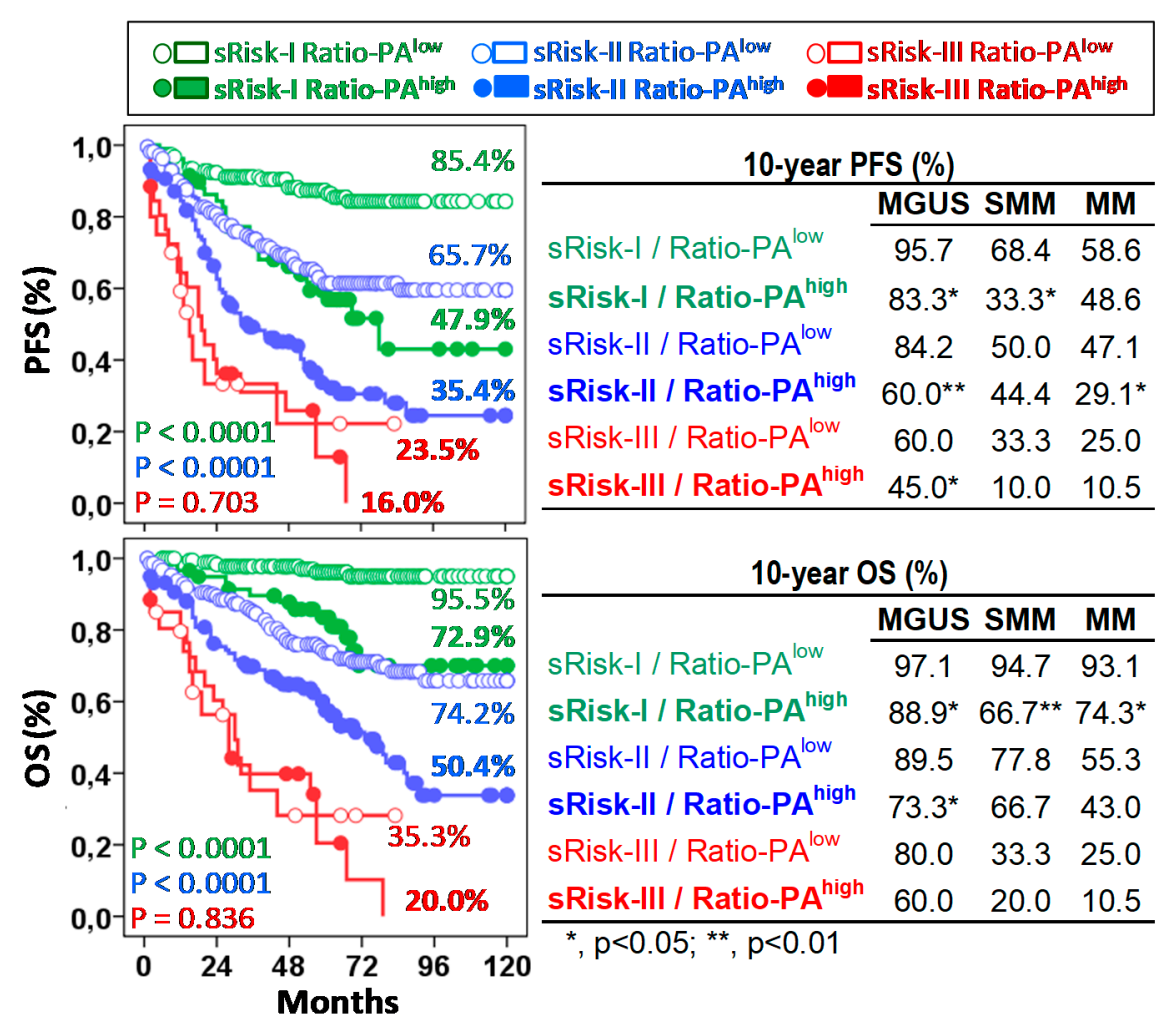

Figure 4. The Ratio-PA of bone marrow plasma cells complements standard risk stratification (sRisk). Left, Kaplan-Meier, and Log-rank tests for progression-free survival (PFS) and overall-survival (OS) of total patients according to Ratio-PA (high or low) in the standard risk groups (Risk-I, -II, and -III). Ten-year PFS and OS rates are indicated for each risk group in the plots. Tables on the right show same information for patients with monoclonal gammopathy of undetermined significance (MGUS), smoldering multiple myeloma (SMM), or multiple myeloma (MM). P estimated in the Log-rank test.

\subsection{Delays in BM Sample Processing Reduces the Prognostic Capacity of the Ratio-PA}

Given that both proliferation and apoptosis rates of BM-PC are functional biological properties, we evaluated the impact that delays in BM sample processing could have in the prognostic capacity of the Ratio-PA. Ratio-PA $(3.7 \pm 0.54,2.45 \pm 0.57$, and $1.1 \pm 0.23)$ and the proportion of patients with Ratio-PA ${ }^{\text {high }}(39.7 \%, 31.3 \%$, and $19.7 \%)$ decreased proportionally to the time elapsed from extraction ( $2 \mathrm{~h}, 4 \mathrm{~h}$, and $24 \mathrm{~h}$, respectively) (Figure 5A). Differences in the distribution of patients by PCN stages or standard risk groups for samples processed at different times, which could have justified the differences observed in their Ratio-PA, were ruled out (Figure $5 \mathrm{~B})$. Nonetheless, patients with Ratio-PA ${ }^{\text {high }}$ showed lower PFS rates than patients with Ratio-PA ${ }^{\text {low }}$ for samples processed in $2 \mathrm{~h}(81.3 \%$ vs. $39.5 \%, p<0.0001), 4 \mathrm{~h}(68.3 \%$ vs. $42.8 \%, p<0.05)$, or $24 \mathrm{~h}(70.9 \%$ vs. $48.3 \%, p<0.01)$, although differences in the PFS and its statistic signification decreased in inverse proportion to the time elapsed until laboratory processing. Besides, Cox regression analysis confirmed that Ratio-PA was an independent prognostic factor in the PFS of PCN patients, but again with decreasing HR $(3.189,1.865$, and 1.890), level of statistic signification $(p<0.0001$, $p<0.01$, and $p<0.05)$, and the Harrell C-statistic $(0.7073 \pm 0.0292,0.6591 \pm 0.0328$, and $0.6728 \pm 0.0402$ ) as time until processing increased (Figure 5C). 

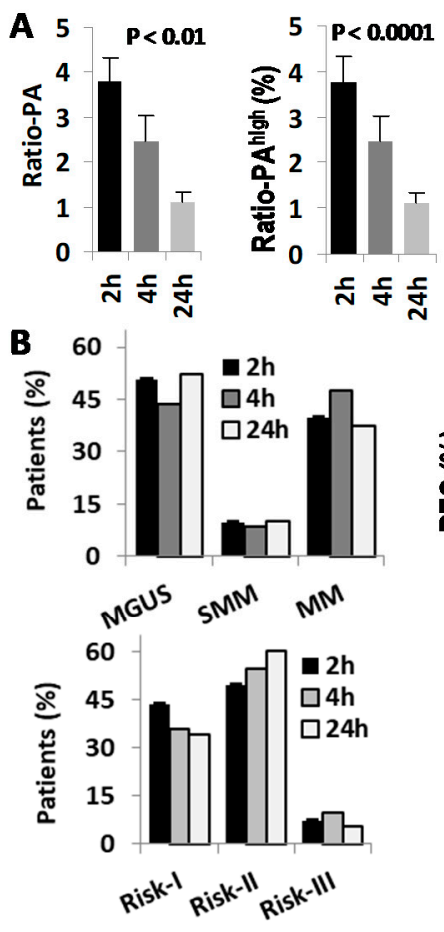
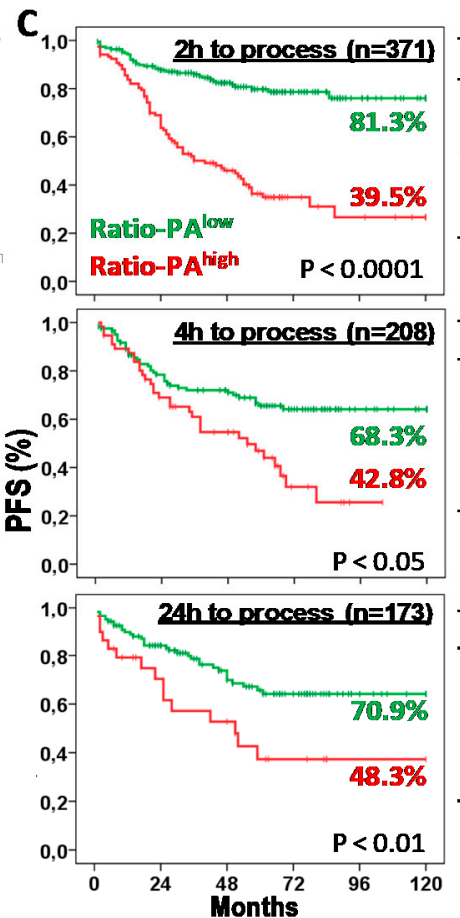

\begin{tabular}{lccc}
\hline Cox for PFS (2h) & HR & 95\%Cl & P \\
\hline Sex & 0.651 & $0.442-0.959$ & 0.0300 \\
Age & 1.026 & $1.007-1.045$ & 0.0001 \\
Standard risk & 1.933 & $1.439-2.596$ & 0.0001 \\
Ratio-PA & 3,189 & $2.103-4.836$ & 0.0001 \\
\hline
\end{tabular}

HR: hazard ratio; $95 \% \mathrm{Cl}: 95 \%$ confidence interval

\begin{tabular}{lccc}
\hline Cox for PFS (4h) & HR & 95\%Cl & P \\
\hline Sex & 0.862 & $0.535-1.389$ & 0.5430 \\
Age & 1.037 & $1.013-1.061$ & 0.0020 \\
Standard risk & 2.431 & $1.624-3.641$ & 0.0001 \\
Ratio-PA & 1.865 & $1.159-2.999$ & 0.0100 \\
\hline
\end{tabular}

HR: hazard ratio; $95 \% \mathrm{Cl}: 95 \%$ confidence interval

\begin{tabular}{lccc}
\hline Cox for PFS (24h) & HR & 95\%Cl & P \\
\hline Sex & 0.607 & $0.329-1.118$ & 0.1090 \\
Age & 1.024 & $0.996-1.054$ & 0.0830 \\
Standard risk & 2.725 & $1.369-5.422$ & 0.0040 \\
Ratio-PA & 1.890 & $0.972-3.674$ & 0.0500 \\
\hline HR: hazard ratio; 95\%Cl: $95 \%$ confidence interval
\end{tabular}

Figure 5. Time from bone marrow (BM) extraction to laboratory processing reduces the prognostic capacity of the Ratio-PA. (A) Ratio-PA of BM plasma cells and proportion of patients with Ratio-PA ${ }^{\text {high }}$ for samples processed $2 \mathrm{~h}, 4 \mathrm{~h}$, or $24 \mathrm{~h}$ after BM extraction. (B) Distribution of patients by the plasma cell neoplasm (PCN) stage and the standard risk (Risk) group according to the processing time. (C) Kaplan-Meier and Log-rank tests for progression-free survival (PFS) according to Ratio-PA (high/low) in total PCN patients and according to the time until processing; and Cox regression analysis of PFS for sex, age, standard risk stratification, and Ratio-PA for samples processed $2 \mathrm{~h}, 4 \mathrm{~h}$, or $24 \mathrm{~h}$ after BM extraction.

\subsection{Tandem ASCT with VTd or VRd Are the Most Effective First-Line Treatments for Patients with Ratio-PA ${ }^{\text {high }}$}

Finally, to explore which therapies of those used in current clinical practice were the most effective in patients with Ratio-PA ${ }^{\text {high }}$, we evaluated the 10y-OS rate and the relapse rate after SCR in symptomatic MM $(n=254)$, as well as in MGUS $(n=19)$ or SMM $(n=24)$ patients that progressed and required treatment $(n=297$ total). Patients were classified according to the first-line treatment used (Figure 6A). In patients eligible for ASCT, Ratio-PA ${ }^{\text {low }}$ was associated with good $10 y-O S$ rates $(77.4 \%$ vs. $87.5 \%)$ for both PAD/VCD and VRd/VTd treatments, whereas in patients with Ratio-PA high, only VRd/VTd, but not PAD/VCD, were associated with high $10 y$-OS rates $(82.7 \%$ vs. $55.2 \%)$. Patients not eligible for ASCT showed much lower 10y-OS rates, while non-significant differences were observed according to the Ratio-PA ${ }^{\text {low } / \text { high }}(46.1 \%$ vs. $35.6 \%)$.

Higher 10y-OS rates observed in patients with Ratio-PA ${ }^{\text {high }}$ treated with ASCT and VRd/VTd were related to a lower relapse rate than the one for patients treated with ASCT and PAD/VCD or No-ASCT $(27.8 \%$ vs. $73.7 \%$ and $78.3 \%, p<0.01)$. In the same line, high 10y-OS rates observed in patients with Ratio-PA ${ }^{\text {low }}$ treated with ASCT, either with $\mathrm{PAD} / \mathrm{VCD}$ or VRd/VTd, were associated with low relapse rates, $37.5 \%$ and $44.4 \%$ respectively, compared to the relapse rate of patients not eligible for ASCT (63.6\%) (Figure 6B).

Patients who did not relapse in the first six months after SCR showed higher 10y-OS rates compared to those who relapsed $(86.0 \%$ vs. $51.6 \%, p<0.0001)$. As expected, the Ratio-PA (low/high) did not have a significant impact on the 10y-OS rates of patients who did not relapse $(87.0 \%$ vs. $84.6 \%)$; however, Ratio-PA ${ }^{\text {low }}$ identified patients who, after relapse, showed higher 10y-OS rates than those with Ratio-PA ${ }^{\text {high }}(72.7 \%$ vs. $41.0 \%$, $p<0.05$ ) (Figure 6C). 
A

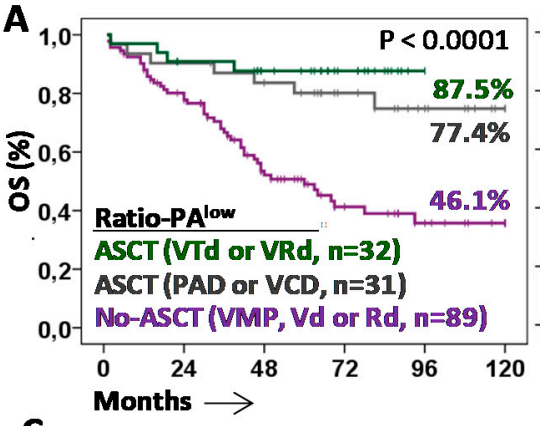

C

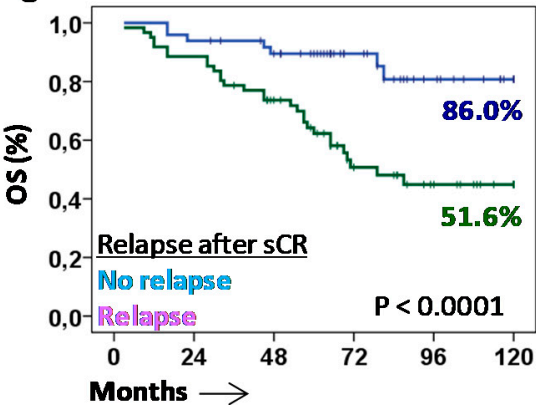

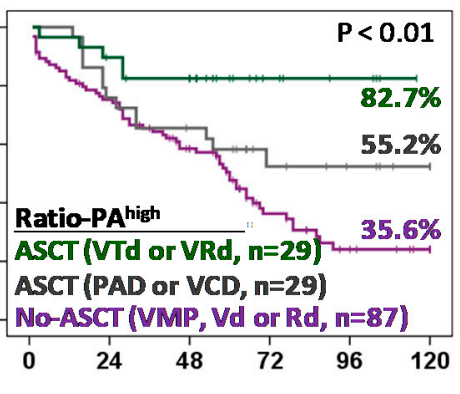

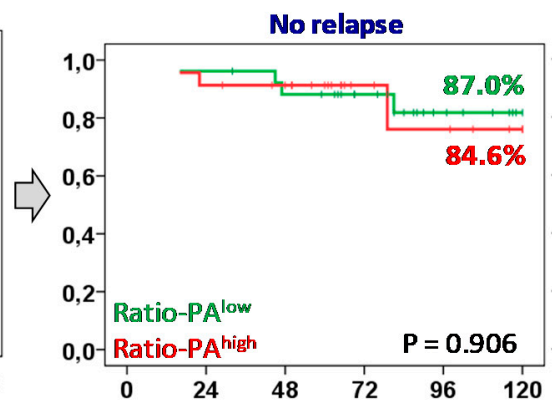

B Ratio-PAlow $(\mathrm{P}=0.325)$

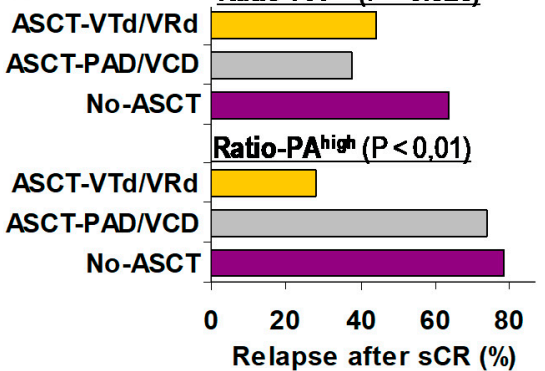

Relapse after SCR (\%)

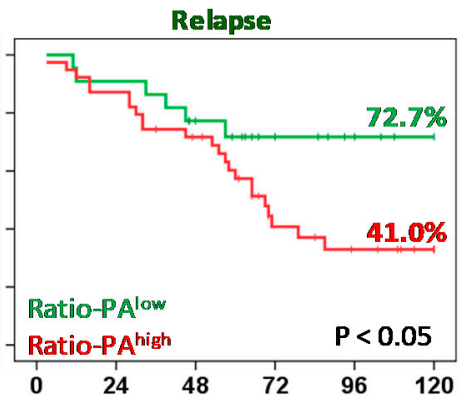

Figure 6. Autologous stem cell transplantation (ASCT) with VTd or VRd is the only effective first-line treatment for MM patients with Ratio-PA ${ }^{\text {high }}$. (A) Kaplan-Meier and Log-rank tests for overall survival (OS) for patients with low or high Ratio-PA according to the type of first-line treatment: No-ASCT with VMP, Vd or Rd; ASCT with PAD or VCD; or ASCT with VTd or VRd. (B) Percentage of patients who relapsed after stringent complete response (sCR) with negative minimal residual disease (MDR-) for low or high Ratio-PA and the three types of treatments. (C) Kaplan-Meier and Log-rank tests for OS according to relapse after $\mathrm{SCR}$, and according to the Ratio-PA.

To further explore the impact of Ratio-PA in the outcome of patients requiring antimyeloma treatment, Supplementary Figure S1 shows the impact of Ratio-PA according to their eligibility for ASCT or their relapse status in the RISS stages. In ASCT-ineligible patients, only those with RISS-I and Ratio-PA ${ }^{\text {high }}$ showed lower 10y-OS. In ASCT-eligible patients, RISS-I, RISS-II, and RISS-III stages with Ratio-PA ${ }^{\text {high }}$ showed lower 10y-OS. In patients without relapse, Ratio-PA ${ }^{\text {high }}$ did not lead to differences in the $10 \mathrm{y}$-OS in patients with RISS-I, but the survival rate was lower in those with RISS-II and RISS-III. In relapsed patients with RISS-I and RISS-II, the Ratio-PA ${ }^{\text {high }}$ led to lower 10y-OS. Nonetheless, these results should be confirmed in larger series due to the reduced number of patients in some subgroups.

\section{Discussion}

Plasma cell neoplasms with a prevalence $>3 \%$ on population aged $\geq 50$ ( $>5 \%$ on aged $>70$ ) for MGUS $[9,10]$ and close to $1 \%$ for MM are one of the most common pathologies in hematology clinics worldwide. Although most of them are asymptomatic, $1 \%$ yearly evolves to a symptomatic PCN that requires treatment, as do patients diagnosed of MM. Fortunately, effective risk stratification methods revised in recent years $[7,8,30]$ have significantly contributed to rationalizing clinical follow-up and therapeutic management of these patients. However, substantial clinical heterogeneity in presentation and course is observed among patients within the same risk status or under comparable therapy regimens, underlining critical differences in neoplastic PC biology and its resistance to current antimyeloma drugs. This study, performed in a large series of patients under current standard treatments and followed-up for a period of 10 years (mean \pm SD, $55.5 \pm 39$ months), shows that proliferation and apoptosis rates of the neoplastic cells significantly determined the progression of the disease and the survival of patients with asymptomatic PCNs and also with symptomatic MM that required treatment. As suggested by our data, the net growth of the tumor estimated as a Ratio-PA of the BM-PCs could determine the aggressiveness of 
the disease and its resistance to current treatments. Our results also reveal two issues of crucial relevance for the clinical management of these patients: firstly, patients with high net tumor growth (Ratio-PA ${ }^{\text {high }}$ ) will respond mostly to first-line therapies including VTd or VRd associated with ASCT, while PCNs with low net tumor growth will show comparable good results with first-line therapies including PAD/VCD or VTd/VRd associated with ASCT; and secondly, proliferation and apoptosis of neoplastic PC should be analyzed in the shortest possible time from BM extraction (preferably $<2 \mathrm{~h}$ ), since time and/or transport alter these functional characteristics of the tumor cell, reducing the prognostic capacity of the Ratio-PA and consequently worsening the correct decision-making in both premalignant and symptomatic PCNs.

Indeed, delays in BM sample processing seemed to affect the prognostic capacity of Ratio-PA. Nonetheless, its independent predictive value remained valid, although it decreased, even in samples that were analyzed $24 \mathrm{~h}$ after extraction. This is in agreement with numerous studies in PCNs demonstrating a prognostic capacity of either the proliferation rate, [14-19] the apoptosis rate [20], or Ratio-PA [28,29]. Although, in light of our results, these studies may have underestimated the prognostic capacity of these parameters, it has been well-established that the PC proliferation rate is one of the most important independent prognostic factors, a specific marker of MM aggressiveness [31-33] and an early marker for disease progression and death [31,34]. However, our data suggest that the inverse relationship between BM-PC proliferation and apoptosis and particularly the balance established between these two parameters is what would ultimately determine the expandability and aggressiveness of the neoplastic PC, and would explain why Ratio-PA was the parameter with the highest predictive value in our PCN series. In fact, immunomodulatory therapies base their anti-myeloma action on the induction of PC apoptosis, which could help to explain why ASCT eligible patients treated with IMiDs showed the best outcome in our series [22,23]. It has been reported that the neoplastic population in MM consists of three clonally-related compartments [35]: (1) self-maintaining stem-cells, (2) growth fraction, and (3) differentiated non-proliferative PCs that will die by apoptosis and necrosis. High Ratio-PA would be indicative of an imbalance between these compartments, in favor of the proliferative one, which would justify a greater aggressiveness and a higher progression rate in these patients.

Improvement of clinical outcomes in MM with the introduction of immunomodulatory drugs has caused some biomarkers to lose their prognostic value, and has made it necessary to redefine the stratification criteria to adjust their predictive capacity $[7,8,30]$. However, the clinical variability observed among patients with the same risk makes it necessary to complement the standard risk stratification with biologically meaningful biomarkers also reassessed for current therapies. In this study, the prognostic capacity of the Ratio-PA was re-evaluated for current treatments in $\mathrm{MM}$, and it was found that not only does it continue to maintain its independent prognostic capacity, but it is also capable of complementing the RISS. Ratio-PA ${ }^{\text {high }}$ identified $24.0 \%$ of low standard risk patients who showed rates of PFS and OS similar to patients with intermediate risk. Furthermore, Ratio-PA ${ }^{\text {high }}$ identified $35.2 \%$ of intermediate-risk patients whose survival curves were closed to those at high standard risk. These patients could have benefited from first-line treatments reserved for high-risk patients. Moreover, if eligible for ASCT, these patients should receive regimens based on VTd or VRd associated to ASCT, the only ones that in our series seem to be effective against PC neoplasms with a high net tumor growth.

Unfortunately, Ratio-PA was unable to provide additional information on the prognosis of patients not eligible for ASCT, since all of them presented an unfavorable clinical course irrespective of the proliferation or apoptosis rates of their neoplastic cells. An exception was ASCT non-eligible patients with RISS-I, where Ratio-PA ${ }^{\text {high }}$ identified a subset of patients at higher risk. However, a Ratio-PA ${ }^{\text {low }}$ at diagnosis would point at $36 \%$ of cases that relapsed after sCR and then had prolonged survival. In contrast, Ratio-PA ${ }^{\text {high }}$ predicted a cohort of patients with much poorer OS who could benefit from consolidation therapy, tandem ASCT, or intensive maintenance after relapse [36]. Recently, it has been 
described that evaluating PC proliferative index post-transplant is a powerful predictor of prognosis in myeloma patients failing to achieve a complete response [37]. Nonetheless, our data suggest that this is a characteristic that could be fixed from the diagnosis. Finally, Ratio-PA ${ }^{\text {high }}$ did not impact the good clinical course of patients with RISS-I who maintained sCR beyond 6 months post-ASCT, although it could be pointing at RISS-II and RISS-III patients with worse clinical course, even though they maintained early sCR post-ASCT.

Although it should be confirmed in larger series, our results suggest that Ratio-PA could be helpful in the clinical management of SMM patients. Excluding ultra-highrisk SMM patients (risk of progression $>80 \%$ in the first two years) who should be diagnosed as symptomatic MM [38,39], the optimal time to treat SMM patients remains controversial [40-42]. In our series, Ratio-PA ${ }^{\text {high }}$ identified $29.8 \%$ of SMM patients with $35.3 \%$ 10y-PFS who could have benefited from an early treatment, [43] since safer and more effective therapies are now available. Watchful waiting was appropriate in an era of only alkylating agents and corticosteroids, but is no longer justifiable for these high-risk patients [39].

Ratio-PA analysis could also facilitate risk-adapted follow-up and clinical management in MGUS. MGUS progression to malignant PCNs occurs at a rate of $1 \%$ per year [11]. However, in our series, Ratio-PA high pointed out patients with a risk of progression and death 3.2 and 3.4 times higher, respectively. Shorter OS of MGUS patients with Ratio$\mathrm{PA}^{\text {high }}$ supports the possibility of a direct negative effect of the monotypic clone inducing severe organ damage, such as by favoring thrombosis, infection, or osteoporosis, amongst others; [44] therefore, it would be reasonable to assess the possibility of early treatment in these high-risk MGUS cases.

Altogether, these results show that the proliferation-to-apoptosis ratio (Ratio-PA) of PC, estimated at diagnosis by flow cytometry in the shortest possible time from BM extraction (preferably $<2 \mathrm{~h}$ ), offers a prognostic biomarker that complements standard risk stratification and helps to guide the clinical management of pre-malignant and symptomatic PCNs. Our results also show that every effort should be made to provide first-line therapies including VTd or VRd associated with ASCT to patients with Ratio-PA ${ }^{\text {high }}$, at higher risk of progression and death. Finally, Ratio-PA ${ }^{\text {high }}$ predicted a cohort of patients who could benefit from consolidation therapy, tandem ASCT, or intensive maintenance when they relapse after stringent complete response.

\section{Patients and Methods}

\subsection{Patients and Samples}

EDTA anti-coagulated BM samples were obtained at diagnosis from 639 consecutive patients with PCNs in regular clinical practice from seven hospitals in the Region of Murcia, Spain. BM samples were also obtained for MRD assessment at three and six months after ASCT, and under the suspicion of loss of sCR. Patients were enrolled between 2010 and 2017, and followed-up until February 2021. This study was approved by the Research Ethics Committee Institutional Review Board (IRB-00005712). Written informed consent was obtained from all patients in accordance with the Declaration of Helsinki.

Following the IMWG criteria [8], patients were classified in 316 MGUS, 57 SSM, and 266 MM. Standard risk stratification (sRisk) in MGUS [30], SMM [7], and MM [8] was done following updated criteria. Patients were grouped as low (Risk-I), intermediate (Risk-II), and high (Risk-III) risk. In MGUS, disease progression was computed when it progressed to SMM or MM. In SMM and MM progression, complete response (CR) and relapse were estimated following the IMWG Uniform Response Criteria for Multiple Myeloma [39,45]. Treatments and management were at the discretion of the hematologists based on patient condition and tumor risk. Briefly, conventional first-line therapy for patients not eligible for ASCT included bortezomib, melphalan, and prednisone (VMP), bortezomib and dexamethasone $(\mathrm{Vd})$, or more recently, lenalidomide and dexamethasone (Rd). In ASCT-eligible patients, first-line therapy included bortezomib, cyclophosphamide, dexamethasone (VCD) or bortezomib, doxorubicin, and dexamethasone (PAD) or more 
recently bortezomib, thalidomide, and dexamethasone (VTd) or bortezomib, lenalidomide, and dexamethasone (VRd), and ASCT conditioning with melphalan $200 \mathrm{mg} / \mathrm{m}^{2}$ (dose ranging from 200 to $100-140 \mathrm{mg} / \mathrm{m}^{2}$ in the case of renal impairment).

\subsection{Immunophenotyping, $M R D$, Proliferation, and Apoptosis Analyses}

Immunophenotypes of BM-PC and MRD analyses were performed in a minimum of $1 \times 10^{6}$ or $2 / 3 \times 10^{6}$ white cells, respectively, with FACSCanto-II and DIVA-Software (Becton Dickinson; BD; San Jose, CA, USA) following consensus criteria $[4,46,47]$ (described in more detail in Figure 7). Briefly, total PCs were identified as CD $38^{+++} \mathrm{CD} 138^{+/++}$ events and aberrant $\mathrm{PC}$ as $\mathrm{CD} 45^{\text {low } / \text { negative }}$ and/or CD19low/negative and/or CD20 ${ }^{+}$and/or $\mathrm{CD} 27^{\text {low/negative }}$ and/or $\mathrm{CD}^{+} 6^{+}$and/or monoclonal restriction for the heavy and/or light immunoglobulin chains. Mature B lymphocytes were defined as low FSC/SSC $\mathrm{CD} 19^{+} \mathrm{CD} 45^{++} \mathrm{CD} 38^{-/ \text {dim }}$ events.
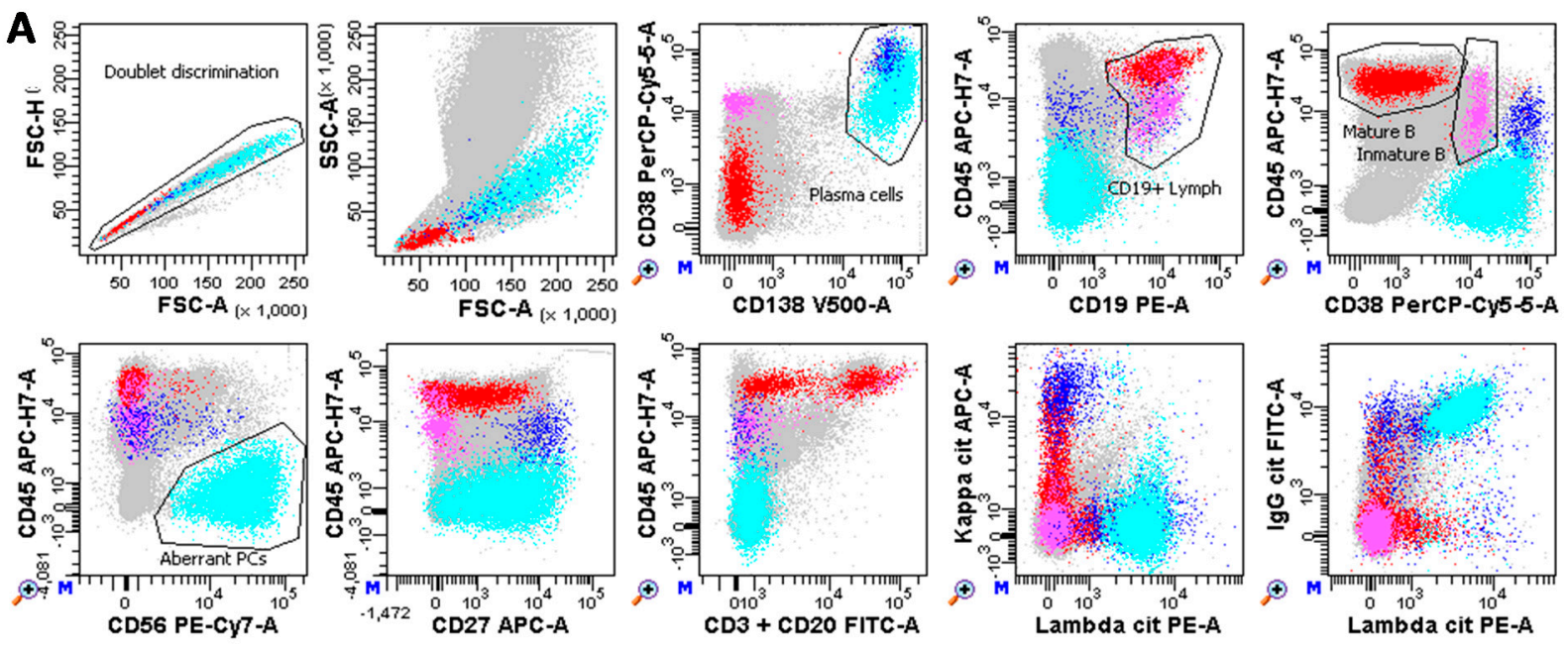

B

Multiple myeloma
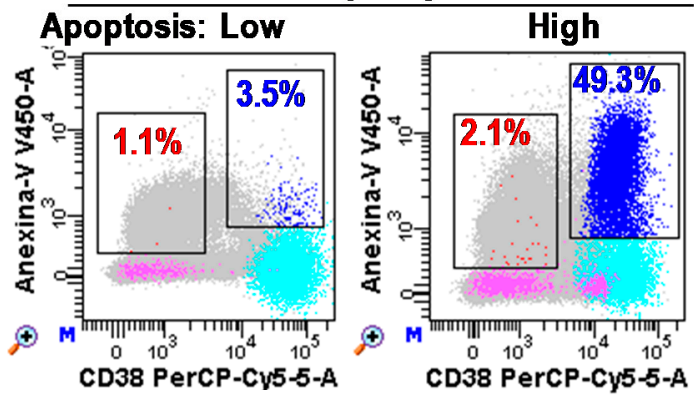

C

Multiple myeloma

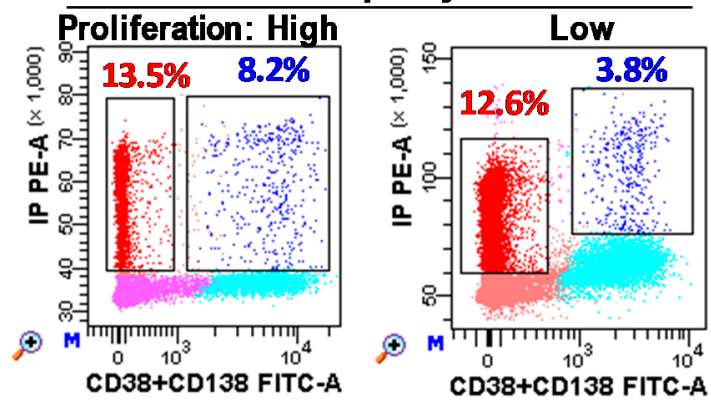

Figure 7. Plasma cell (PC) immunophenotyping. (A) Flow cytometry analysis of bone marrow samples performed with FACSCanto-II and DIVA Software (Becton Dickinson, San Jose, CA, USA). Photomultiplier (PMT) voltages were adjusted daily using CS\&T beads (BD). Fluorescence compensations were finely adjusted using negative events as reference for each fluorochrome. A total of three million white cells were stained for each tube, tube-1: CD3\&CD20 FITC, CD19 PE, CD38 PerCP-Cy5.5, CD56 PE-Cy7, CD27 APC, CD45 APC-Cy7, Annexin-V V450, and CD138 BV510 (BD); and tube-2: cyIgG, cyIgA, cyIgD, or cyIgM FITC, cyLambda PE, CD38 PerCP-Cy5.5, CD56 PE-Cy7, cyKappa APC, CD45 APC-Cy7, CD19 BV421, and CD138 BV510 (BD). One million cells were recorded for each tube. After doublet discrimination (in a FSC-H/SSC-A dotplot), total PC (Blue) were identified as CD $38^{+++} \mathrm{CD} 138^{+/++}$events. Aberrant PC (cyan) were identified as CD45 low/negative and/or CD19low/negative and/or CD20 ${ }^{+}$and/or CD27low/negative and/or CD56 ${ }^{+}$and/or monoclonal restriction for the heavy and/or light immunoglobulin chains (specific gating strategy was follow for each patient based on their phenotype). Mature B cells (red) were identified as lymphocytes (FSC/SSClow) CD $19^{+} \mathrm{CD} 45^{++} \mathrm{CD} 38^{-/+}$low. Immature B lymphocytes (pink) were defined as $\mathrm{CD} 19^{+} \mathrm{CD} 45^{\text {low }} \mathrm{CD} 38^{++}$. Grey cells are non-B non-PC cells. (B,C) Bone marrow PCs $\left(\mathrm{CD} 38^{+} \mathrm{CD} 138^{+}\right)$from MM patients with low and high apoptosis (Anexin- $\mathrm{V}^{+}$blue and red events for PCs and B lymphocytes, respectively) and proliferation rates $(\mathrm{S}+\mathrm{G} 2 / \mathrm{M}$ phases of the cell cycle), respectively. 
The proliferation rate of aberrant PC was estimated as the percentage of CD38/CD138 ${ }^{+}$ cells in the Synthesis + G2/M phases of the cell cycle by using Cycloscope-MM (Cytognos, Salamanca, Spain). Apoptosis rate of aberrant PC was estimated as the percentage of Anexin- $\mathrm{V}^{+}$PCs minus the percentage of Anexin- $\mathrm{V}^{+}$mature B lymphocytes by using antiAnexin-V V450 (BD).

Given that both proliferation and apoptosis rates of BM-PC are functional biological properties that can be compromised by the time elapsed from extraction to laboratory processing, the transport, and/or storage conditions, we compared the Ratio-PA values and its prognostic capacity in in-house samples (analyzed in less than $2 \mathrm{~h}, n=293$ ), and in external samples which were processed in less than $4 \mathrm{~h}(n=173)$ or $24 \mathrm{~h}(n=142)$, depending on whether samples were shipped on the same day or the day after the BM extraction. $\mathrm{BM}$ samples were kept at room temperature and protected from extreme temperatures during transport. As described above, the apoptosis rate of mature B lymphocytes was extracted from the PC apoptosis rate as an internal control so as to minimize the impact of process times.

\subsection{Fluorescent In Situ Hybridization (FISH)}

Cytogenetic abnormalities were evaluated in an interphase nucleus from BM-PCs purified using a RosetteSep ${ }^{\circledR}$ Human Multiple-Myeloma-Cell Enrichment Cocktail (Stemcell Technologies, Grenoble, France). The following FISH probes from Metasystems (Altlussheim, Germany) were used to evaluate: translocations of the immunoglobulin heavy chain gene region (IGH) with break-apart IGH probe (cut-off: 3\%) and dual fusion probes to determine the most common IGH partners CCND1 (cut-off: 2\%), FGFR3 (cut-off: 2\%), MAF (cut-off: $2 \%$ ), and MAFB (cut-off: $2 \%$ ); the copy number of chromosomes 5, 9, and 15 with 5p15/9q22/15q22 hyperdiploidy probes (cut-off: 10\%); amplification/deletion of 17p13 (TP53) and 17q22 (LPO/MPO) with locus-specific probes (cut-off: 10\%); amplification/deletion of 1q21-22 (CKS1B) and 1p32.3 (CDKN2C) with locus-specific probes (cut-off: 10\%), and monosomy-13/deletion 13q14.2 (DLEU1) and 13q34 (LAMP1) with locus-specific probes (cut-off: 10\%). For each probe, 300 plasma cells were analyzed with Metafer (Metasystems).

\subsection{Statistical Analysis}

Statistical analyses were performed using SPSS version 15.0 (SPSS Inc, Chicago, IL, USA). Analysis of variance (ANOVA) and least significant difference (LSD) post hoc tests were used to analyze continuous variables. The receiver operating characteristic (ROC) was used to explore patient PFS and to determine the optimal cutoff values for proliferation and apoptosis rates, as well as for the proliferation-to-apoptosis ratio (Ratio-PA). PFS was estimated as months from the diagnosis date to disease progression or death. Survival curves were plotted according to the Kaplan-Meier method. The log-rank test was used to estimate significant differences. Multivariate analyses of prognostic factors for PFS and OS were performed using the Cox proportional hazards model (stepwise regression). The hazard ratio (HR) and 95\% confidence interval were estimated. The Harrell C-statistic was obtained using STATA-14 (Somersd package, College Station, TX, USA). $p<0.05$ was considered statistically significant.

Supplementary Materials: The following are available online at https:/ / www.mdpi.com/article/ 10.3390/ijms22083895/s1, Supplementary Figure S1: Predictive value of Ratio-PA in plasma cell neoplasm patients requiring treatment.

Author Contributions: Conceptualization, A.M. and A.P.; Data curation, M.A.V.-M., J.A.C., L.G., M.F.S.-R., M.D.M.-H. and M.M.; Formal analysis, A.M., J.A.C., M.A.V.-M. and A.P.; Funding acquisition, A.M. and M.M.; Methodology, A.M., V.C., M.B., M.C.G.-G., J.A.C., M.F.S.-R. and M.D.M.-H.; Project administration, A.M.; Supervision, A.M. and J.A.C.; Validation, A.M.; Visualization, A.M., J.A.C. and A.P.; Writing — original draft, A.M.; Writing—review \& editing, A.M. and J.A.C. All authors have read and agreed to the published version of the manuscript. 
Funding: This work was funded by MINECO — Health Institute Carlos III (ISCiii, PI20/00161); Co-funded by European Regional Development Fund (ERDF), "A way to make Europe".

Institutional Review Board Statement: This study was approved by the Research Ethics Committee Institutional Review Board (IRB-00005712).

Informed Consent Statement: Written informed consent was obtained from all patients in accordance with the Declaration of Helsinki.

Data Availability Statement: Not applicable.

Acknowledgments: We would like to acknowledge hematologists collaborating in the enrolment of patients: Catalina Cava Almohalla, Antonio Martínez Frances, Begoña Muiña Juarez, Horacio Cano Gracia, Victoriano Beltran Agullo and laboratory technicians María Carmen Martínez Solano, María Dolores García Arnao and María Elena Bernal Moreno.

Conflicts of Interest: The authors declare no conflict of interest. The funders had no role in the design of the study; in the collection, analyses, or interpretation of data; in the writing of the manuscript, or in the decision to publish the results.

\section{References}

1. San-Miguel, J.F.; Mateos, M.V. Can multiple myeloma become a curable disease? Haematologica 2011, 96, 1246-1248. [CrossRef] [PubMed]

2. $\quad$ van de Donk, N.W.C.J.; Mutis, T.; Poddighe, P.J.; Lokhorst, H.M.; Zweegman, S. Diagnosis, risk stratification and management of monoclonal gammopathy of undetermined significance and smoldering multiple myeloma. Int. J. Lab. Hematol. 2016, 38, 110-122. [CrossRef] [PubMed]

3. Kyle, R.A.; Durie, B.G.M.; Rajkumar, S.V.; Landgren, O.; Blade, J.; Merlini, G.; Kröger, N.; Einsele, H.; Vesole, D.H.; Dimopoulos, M.; et al. Monoclonal gammopathy of undetermined significance (MGUS) and smoldering (asymptomatic) multiple myeloma: IMWG consensus perspectives risk factors for progression and guidelines for monitoring and management. Leukemia 2010, 24, 1121-1127. [CrossRef] [PubMed]

4. Pérez-Persona, E.; Vidriales, M.-B.; Mateo, G.; García-Sanz, R.; Mateos, M.-V.; de Coca, A.G.; Galende, J.; Martín-Nuñez, G.; Alonso, J.M.; de Las Heras, N.; et al. New criteria to identify risk of progression in monoclonal gammopathy of uncertain significance and smoldering multiple myeloma based on multiparameter flow cytometry analysis of bone marrow plasma cells. Blood 2007, 110, 2586-2592. [CrossRef] [PubMed]

5. Lakshman, A.; Rajkumar, S.V.; Buadi, F.K.; Binder, M.; Gertz, M.A.; Lacy, M.Q.; Dispenzieri, A.; Dingli, D.; Fonder, A.L.; Hayman, S.R.; et al. Risk stratification of smoldering multiple myeloma incorporating revised IMWG diagnostic criteria. Blood Cancer J. 2018, 8, 59. [CrossRef] [PubMed]

6. Mateos, M.-V.; Kumar, S.; Dimopoulos, M.A.; González-Calle, V.; Kastritis, E.; Hajek, R.; De Larrea, C.F.; Morgan, G.J.; Merlini, G.; Goldschmidt, H.; et al. International Myeloma Working Group risk stratification model for smoldering multiple myeloma (SMM). Blood Cancer J. 2020, 10, 102. [CrossRef]

7. Wu, V.; Moshier, E.; Leng, S.; Barlogie, B.; Cho, H.J.; Jagannath, S.; Madduri, D.; Mazumdar, M.; Parekh, S.; Chari, A. Risk stratification of smoldering multiple myeloma: Predictive value of free light chains and group-based trajectory modeling. Blood Adv. 2018, 2, 1470-1479. [CrossRef]

8. Rajkumar, S.V. Multiple myeloma: 2018 update on diagnosis, risk-stratification, and management. Am. J. Hematol. 2018, 93, 1091-1110. [CrossRef]

9. Wadhera, R.K.; Rajkumar, S.V. Prevalence of monoclonal gammopathy of undetermined significance: A systematic review. Mayo Clin. Proc. 2010, 85, 933-942. [CrossRef]

10. Kyle, R.A.; Therneau, T.M.; Rajkumar, S.V.; Larson, D.R.; Plevak, M.F.; Offord, J.R.; Dispenzieri, A.; Katzmann, J.A.; Melton, L.J. Prevalence of monoclonal gammopathy of undetermined significance. N. Engl. J. Med. 2006, 354, 1362-1369. [CrossRef]

11. Kyle, R.A.; Larson, D.R.; Therneau, T.M.; Dispenzieri, A.; Kumar, S.; Cerhan, J.R.; Rajkumar, S.V. Long-Term Follow-up of Monoclonal Gammopathy of Undetermined Significance. N. Engl. J. Med. 2018, 378, 241-249. [CrossRef]

12. Kyle, R.A.; Remstein, E.D.; Therneau, T.M.; Dispenzieri, A.; Kurtin, P.J.; Hodnefield, J.M.; Larson, D.R.; Plevak, M.F.; Jelinek, D.F.; Fonseca, R.; et al. Clinical course and prognosis of smoldering (asymptomatic) multiple myeloma. N. Engl. J. Med. 2007, 356, 2582-2590. [CrossRef]

13. Gagelmann, N.; Eikema, D.-J.; Koster, L.; Caillot, D.; Pioltelli, P.; Lleonart, J.B.; Reményi, P.; Blaise, D.; Schaap, N.; Trneny, M.; et al. Tandem Autologous Stem Cell Transplantation Improves Outcomes in Newly Diagnosed Multiple Myeloma with Extramedullary Disease and High-Risk Cytogenetics: A Study from the Chronic Malignancies Working Party of the European Society for Blood and Marrow Tran. Biol. Blood Marrow Transplant. 2019, 25, 2134-2142. [CrossRef]

14. Scudla, V.; Ordeltova, M.; Minarik, J.; Dusek, L.; Zemanova, M.; Bacovsky, J. Prognostic significance of plasma cell propidium iodide and annexin- $\mathrm{V}$ indices and their mutual ratio in multiple myeloma. Neoplasma 2006, 53, 213-218. 
15. Minarik, J.; Scudla, V.; Ordeltova, M.; Pika, T.; Bacovsky, J.; Steinbach, M.; Kumar, V.; Van Ness, B. Combined measurement of plasma cell proliferative and apoptotic index in multiple myeloma defines patients with good and poor prognosis. Leuk. Res. 2011, 35, 44-48. [CrossRef]

16. Minarík, J.; Scudla, V.; Ordeltová, M.; Bacovský, J.; Zemanová, M. Evaluation of plasma cell propidium-iodide and annexin-V indices: Their relation to prognosis in multiple myeloma. Biomed. Pap. Med. Fac. Univ. Palacky. Olomouc. Czech. Repub. 2005, 149, 271-274. [CrossRef]

17. Madan, S.; Kyle, R.A.; Greipp, P.R. Plasma cell labeling index in the evaluation of smoldering (asymptomatic) multiple myeloma. Mayo Clin. Proc. 2010, 85, 300. [CrossRef] [PubMed]

18. Aljama, M.A.; Sidiqi, M.H.; Lakshman, A.; Dispenzieri, A.; Jevremovic, D.; Gertz, M.A.; Lacy, M.Q.; Buadi, F.K.; Dingli, D.; Muchtar, E.; et al. Plasma cell proliferative index is an independent predictor of progression in smoldering multiple myeloma. Blood Adv. 2018, 2, 3149-3154. [CrossRef] [PubMed]

19. Dhodapkar, M.V.; Sexton, R.; Waheed, S.; Usmani, S.; Papanikolaou, X.; Nair, B.; Petty, N.; Shaughnessy, J.D.; Hoering, A.; Crowley, J.; et al. Clinical, genomic, and imaging predictors of myeloma progression from asymptomatic monoclonal gammopathies (SWOG S0120). Blood 2014, 123, 78-85. [CrossRef] [PubMed]

20. Oancea, M.; Mani, A.; Hussein, M.A.; Almasan, A. Apoptosis of multiple myeloma. Int. J. Hematol. 2004, 80, 224-231. [CrossRef]

21. Spets, H.; Strömberg, T.; Georgii-Hemming, P.; Siljason, J.; Nilsson, K.; Jernberg-Wiklund, H. Expression of the bcl-2 family of proand anti-apoptotic genes in multiple myeloma and normal plasma cells: Regulation during interleukin-6(IL-6)-induced growth and survival. Eur. J. Haematol. 2002, 69, 76-89. [CrossRef]

22. Holstein, S.A.; McCarthy, P.L. Immunomodulatory Drugs in Multiple Myeloma: Mechanisms of Action and Clinical Experience. Drugs 2017, 77, 505-520. [CrossRef]

23. Mitsiades, N.; Mitsiades, C.S.; Poulaki, V.; Chauhan, D.; Fanourakis, G.; Gu, X.; Bailey, C.; Joseph, M.; Libermann, T.A.; Treon, S.P.; et al. Molecular sequelae of proteasome inhibition in human multiple myeloma cells. Proc. Natl. Acad. Sci. USA 2002, 99, 14374-14379. [CrossRef] [PubMed]

24. Liu, S.; Edgerton, S.M.; Moore, D.H.; Thor, A.D. Measures of cell turnover (proliferation and apoptosis) and their association with survival in breast cancer. Clin. Cancer Res. 2001, 7, 1716-1723. [PubMed]

25. Scudla, V.; Ordeltova, M.; Bacovsky, J.; Vytrasova, M.; Sumna, E.; Martinek, A.; Horak, P. A contribution to examination of propidium iodide and annexin V plasma cells indices in multiple myeloma. Neoplasma 2003, 50, 363-371.

26. Leung, T.-W.; Xue, W.-C.; Cheung, A.N.Y.; Khoo, U.-S.; Ngan, H.Y.S. Proliferation to apoptosis ratio as a prognostic marker in adenocarcinoma of uterine cervix. Gynecol. Oncol. 2004, 92, 866-872. [CrossRef] [PubMed]

27. Kuriyama, H.; Lamborn, K.R.; O’Fallon, J.R.; Iturria, N.; Sebo, T.; Schaefer, P.L.; Scheithauer, B.W.; Buckner, J.C.; Kuriyama, N.; Jenkins, R.B.; et al. Prognostic significance of an apoptotic index and apoptosis/proliferation ratio for patients with high-grade astrocytomas. Neuro Oncol. 2002, 4, 179-186. [CrossRef]

28. Witzig, T.E.; Timm, M.; Larson, D.; Therneau, T.; Greipp, P.R. Measurement of apoptosis and proliferation of bone marrow plasma cells in patients with plasma cell proliferative disorders. Br. J. Haematol. 1999, 104, 131-137. [CrossRef]

29. Scudla, V.; Vlastimil, M.; Ordeltova, M.; Bacovsky, J.; Vytrasova, M.; Horak, P.; Minarik, J. The relationship between proliferation and apoptosis in patients with monoclonal gammopathy of undetermined significance or multiple myeloma. Haematologica 2005, 90, 1713-1714.

30. Rajkumar, S.V.; Kyle, R.A.; Buadi, F.K. Advances in the diagnosis, classification, risk stratification, and management of monoclonal gammopathy of undetermined significance: Implications for recategorizing disease entities in the presence of evolving scientific evidence. Mayo Clin. Proc. 2010, 85, 945-948. [CrossRef]

31. Boccadoro, M.; Marmont, F.; Tribalto, M.; Fossati, G.; Redoglia, V.; Battaglio, S.; Massaia, M.; Gallamini, A.; Comotti, B.; Barbui, T. Early responder myeloma: Kinetic studies identify a patient subgroup characterized by very poor prognosis. J. Clin. Oncol. 1989, 7, 119-125. [CrossRef]

32. San Miguel, J.F.; García-Sanz, R.; González, M.; Moro, M.J.; Hernández, J.M.; Ortega, F.; Borrego, D.; Carnero, M.; Casanova, F.; Jiménez, R. A new staging system for multiple myeloma based on the number of S-phase plasma cells. Blood 1995, 85, 448-455. [CrossRef] [PubMed]

33. Trendle, M.C.; Leong, T.; Kyle, R.A.; Katzmann, J.A.; Oken, M.M.; Kay, N.E.; Van Ness, B.G.; Greipp, P.R. Prognostic significance of the S-phase fraction of light-chain-restricted cytoplasmic immunoglobulin (cIg) positive plasma cells in patients with newly diagnosed multiple myeloma enrolled on Eastern Cooperative Oncology Group treatment trial E9486. Am. J. Hematol. 1999, 61, 232-237. [CrossRef]

34. Steensma, D.P.; Gertz, M.A.; Greipp, P.R.; Kyle, R.A.; Lacy, M.Q.; Lust, J.A.; Offord, J.R.; Plevak, M.F.; Therneau, T.M.; Witzig, T.E. A high bone marrow plasma cell labeling index in stable plateau-phase multiple myeloma is a marker for early disease progression and death. Blood 2001, 97, 2522-2523. [CrossRef] [PubMed]

35. Vacca, A.; Ribatti, D.; Roncali, L.; Dammacco, F. Angiogenesis in B cell lymphoproliferative diseases. Biological and clinical studies. Leuk. Lymphoma 1995, 20, 27-38. [CrossRef] [PubMed]

36. Cavo, M.; Pantani, L.; Petrucci, M.T.; Patriarca, F.; Zamagni, E.; Donnarumma, D.; Crippa, C.; Boccadoro, M.; Perrone, G.; Falcone, A.; et al. Bortezomib-thalidomide-dexamethasone is superior to thalidomide-dexamethasone as consolidation therapy after autologous hematopoietic stem cell transplantation in patients with newly diagnosed multiple myeloma. Blood 2012, 120, 9-19. [CrossRef] [PubMed] 
37. Sidiqi, M.H.; Aljama, M.A.; Jevremovic, D.; Morice, W.G.; Timm, M.; Buadi, F.K.; Warsame, R.; Lacy, M.Q.; Dispenzieri, A.; Dingli, D.; et al. Plasma cell proliferative index post-transplant is a powerful predictor of prognosis in myeloma patients failing to achieve a complete response. Bone Marrow Transplant. 2019, 54, 442-447. [CrossRef]

38. Kastritis, E.; Terpos, E.; Moulopoulos, L.; Spyropoulou-Vlachou, M.; Kanellias, N.; Eleftherakis-Papaiakovou, E.; Gkotzamanidou, M.; Migkou, M.; Gavriatopoulou, M.; Roussou, M.; et al. Extensive bone marrow infiltration and abnormal free light chain ratio identifies patients with asymptomatic myeloma at high risk for progression to symptomatic disease. Leukemia 2013, 27, 947-953. [CrossRef]

39. Rajkumar, S.V.; Dimopoulos, M.A.; Palumbo, A.; Blade, J.; Merlini, G.; Mateos, M.V.; Kumar, S.; Hillengass, J.; Kastritis, E.; Richardson, P.; et al. International Myeloma Working Group updated criteria for the diagnosis of multiple myeloma. Lancet Oncol. 2014, 15, e538-e548. [CrossRef]

40. Zhao, A.-L.; Shen, K.-N.; Wang, J.-N.; Huo, L.-Q.; Li, J.; Cao, X.-X. Early or deferred treatment of smoldering multiple myeloma: A meta-analysis on randomized controlled studies. Cancer Manag. Res. 2019, 11, 5599-5611. [CrossRef]

41. Hernández, J.-Á.; Martínez-López, J.; Lahuerta, J.-J. Timing treatment for smoldering myeloma: Is earlier better? Expert Rev. Hematol. 2019, 12, 345-354. [CrossRef]

42. Kapoor, P.; Rajkumar, S.V. Smoldering Multiple Myeloma: To Treat or Not to Treat. Cancer J. 2015, 25, 65-71. [CrossRef] [PubMed]

43. Mateos, M.-V.; Hernández, M.-T.; Giraldo, P.; de la Rubia, J.; de Arriba, F.; López Corral, L.; Rosiñol, L.; Paiva, B.; Palomera, L.; Bargay, J.; et al. Lenalidomide plus dexamethasone for high-risk smoldering multiple myeloma. N. Engl. J. Med. 2013, 369, 438-447. [CrossRef] [PubMed]

44. $\quad$ van de Donk, N.W.C.J.; Niels, W.C.J.; Palumbo, A.; Johnsen, H.E.; Engelhardt, M.; Gay, F.; Gregersen, H.; Hajek, R.; Kleber, M.; Ludwig, H.; et al. The clinical relevance and management of monoclonal gammopathy of undetermined significance and related disorders: Recommendations from the European Myeloma Network. Haematologica 2014, 99, 984-996. [CrossRef] [PubMed]

45. Durie, B.G.M.; Harousseau, J.L.; Miguel, J.S.; Bladé, J.; Barlogie, B.; Anderson, K.; Gertz, M.; Dimopoulos, M.; Westin, J.; Sonneveld, P.; et al. International uniform response criteria for multiple myeloma. Leukemia 2006, 20, 1467-1473. [CrossRef] [PubMed]

46. Flores-Montero, J.; Sanoja-Flores, L.; Paiva, B.; Puig, N.; García-Sánchez, O.; Böttcher, S.; Van Der Velden, V.H.J.; Pérez-Morán, J.J.; Vidriales, M.B.; García-Sanz, R.; et al. Next Generation Flow for highly sensitive and standardized detection of minimal residual disease in multiple myeloma. Leukemia 2017, 31, 2094-2103. [CrossRef]

47. Kumar, S.; Paiva, B.; Anderson, K.C.; Durie, B.; Landgren, O.; Moreau, P.; Munshi, N.; Lonial, S.; Bladé, J.; Mateos, M.V.; et al. International Myeloma Working Group consensus criteria for response and minimal residual disease assessment in multiple myeloma. Lancet Oncol. 2016, 17, e328-e346. [CrossRef] 